\title{
AN ANTHOLOGY OF THE DISTINGUISHED ACHIEVEMENTS IN SCIENCE AND TECHNIQUE. PART 41: COMPOSITE MATERIALS: THEIR CLASSIFICATION, TECHNOLOGIES OF MAKING, PROPERTIES AND APPLICATION DOMAINS IN MODERN TECHNIQUE
}

Purpose. Preparation of brief scientific and technical review about the state, achievements and prospects of development of works domestic and foreign scientists-specialists on materials and technologists in area of development and creation of composite materials (compos). Methodology. Scientific methods of collection, analysis and analytical treatment of the opened scientific and technical information of world level in area of studies about materials, related to development of basic technologies of making of new perspective compos and their application in a modern technique. Results. A state-of-the-art scientific and technical review is resulted about the state, achievements and prospects on the future in the world of researches on development and creation of new metallic and non-metal compos, possessing as compared to traditional homogeneous materials substantially more high physical and mechanical descriptions. Classification of compos is executed. Technologies of making of basic types of compos, findings a practical wide use enough in an aviation and space-rocket technique, engineering and row of the special areas of modern technique are briefly described. Main properties of basic types of compos and their advantage are indicated before traditional metals and alloys. The basic failings and technical application for today of different compos domains are resulted. Considerable progress is marked in technologies of making and volumes of the use in the frontrank areas of technique of compos. The possible nearest prospects are indicated in the use of compos on the future in a number of stormy developing in the whole world technical areas. Originality. Systematization of the scientific and technical materials, devoted the basic results of works on being in 2016 year of domestic and foreign specialists in area of development, making and application in the modern technique of the most perspective types of compos, known from the sources opened in outer informative space is executed. Practical value. Popularization and deepening for students, engineers and technical specialists and research workers of scientific and technical knowledges in the necessary area of development, creation and application in the modern technique of compos, extending their scientific range of interests and further development of scientific and technical progress in human society. References 22, figures 6.

Key words: composite materials, basic technologies of receipt of compos, advantages of compos before traditional materials, world achievements in creation of compos.

Приведен научно-технический обзор о состоянии, достижениях и перспективах развития работ отечественных и зарубежнных ученых-материаловедов в области разработки и создания композиционных материалов, обладающцх по сравнению с традиционными однородными материалами существенно более высокими физико-механическими характеристиками. Описаны основные классификации, технологии получения, свойства и области применения подобных материалов-композитов в технике. Библ. 22, рис. 6.

Ключевые слова: композиционные материалы, основные технологии получения композитов, преимущества композитов перед традиционными материалами, мировые достижения в создании композитов.

Introduction. Further progressive development in the world of modern technology in mechanical engineering, electrical engineering, electric power, instrument-making, aviation and rocket building industries requires the creation of a variety of new materials with their increasingly high performance properties. Scientists and specialists from many countries of the world engaged in the study of behavior in the field of material science and experimental determination of the physical and technical characteristics of various metals and alloys have long concluded that the creation of inhomogeneous solid compositions with a correct choice of their initial components may lead to new materials with their significantly improved mechanical characteristics compared to known homogeneous materials. Similar materials in materials science are called composite. According to modern concepts, composite material (CM) is an artificially created heterogeneous solid material consisting of two or more components with a clear interface between them [1]. One of the «oldest» and still used throughout the world of CM is a «bulat» containing the finest layers (sometimes strands) of highcarbon steel, which are «glued together» by soft lowcarbon iron [1]. After the reasons for their plasticity, elasticity and strength were scientifically explained in metal science and in the physics of metals, and the main physicochemical pathways of a noticeable increase (strengthening) of the indices of these physical properties were established [2] in the leading material science laboratories of the world, intensive systemic the development of new non-metallic materials with their significantly increased physicomechanical characteristics. In the last decades, materials scientists of the industrially developed countries of the world are actively engaged in scientific and technical search for new CMs, purposefully creating the most promising for 
their physico-mechanical properties for a number of rapidly developing areas of modern technology and relatively cheap in the production of CM (compos).

The goal of the paper is compilation of a brief scientific and technical review on the state, achievements and prospects for the development of materials research in the world in the field of development and production of composites.

1. Classification of composites. In most $\mathrm{CMs}$, which are usually multicomponent materials, the components (components) used in them can be divided into a matrix (continuous throughout the volume of the $\mathrm{CM}$ plastic base) and included in it reinforcing elements (interrupted by the volume of CM reinforcing fillers) that have high strength, rigidity, heat resistance and other physical properties [1-3]. We note that the CM matrix ensures the monolithic nature of the created material, imparts the required shape to the created product, transfers the mechanical stress from one part of the filler medium to the other, protects the reinforcing reinforcement from mechanical damage and provides mechanical and other resistance to overall external forces. Specialists (materials scientists and technologists), varying the compositions of matrices and fillers, their percentage ratio and the spatial orientation of the filler reinforcement in the volume of $\mathrm{CM}$, can now obtain a very wide spectrum of $\mathrm{CM}$ with the required set of their properties [1-3]. In this connection, all the composites by the form of the matrix used in the $\mathrm{CM}$ are now classified into [1]:

- composites with a polymer matrix;

- composites with a metal matrix;

- composites with a ceramic matrix;

- composites with an oxide-oxide system.

By the type of filler used in the CM (reinforcing component), existing and newly created composites are classified into [1]:

- fibrous composites (reinforcing components fibrous structures of non-metals and metals);

- layered composites (reinforcing components separate layered structures, Fig. 1);

- composites such as «filled plastics» (reinforcing components - nano- and microparticles);

- bulk composites having homogeneous dispersed non-metallic and metal structures;

- skeletal composites in which the original structures are filled with a binder.

According to the type of reinforcing filler, fibrous $\mathrm{CM}$ are classified into the following groups [2]:

- fiberglass with glass fibers;

- carbon fibers with carbon fibers;

- boron fibers with boron fibers;

- organic fibers with synthetic threads.

In addition, the CM according to the geometry of the reinforcing element-filler included in their composition is divided into the following main groups $[4,5]$ :
- with zero-dimensional fillers (structural reinforcements), whose dimensions in three spatial dimensions are of the same order;

- with one-dimensional fillers, one of the sizes of which considerably exceeds the other two;

- with two-dimensional fillers, any two sizes which significantly exceed the third.

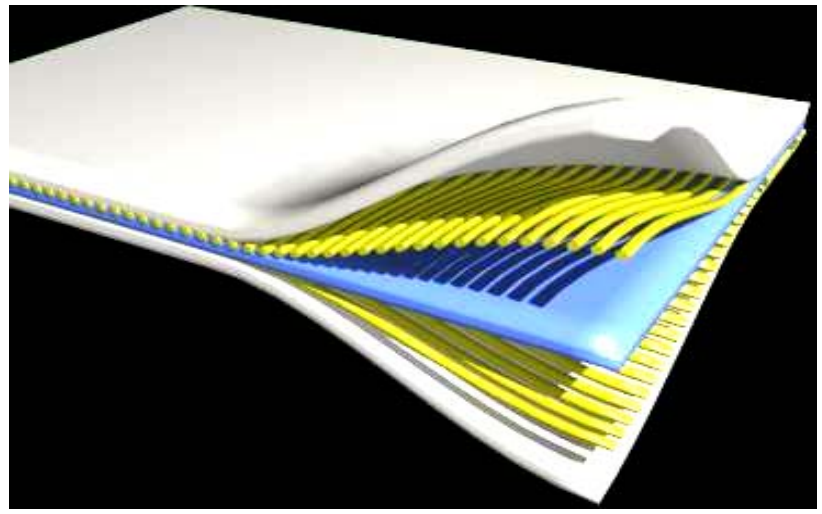

Fig. 1. Layout of individual layers in the CM [1]

According to the arrangement of the reinforcing element-filler, CMs are divided into such groups [4]:

- with an uniaxial (linear) arrangement of the filler reinforcement in the matrix in the form of parallel fibers, filaments and filamentary single crystals;

- with a biaxial (planar) arrangement of reinforcing filler, mats from filamentary single crystals and metal foils in a matrix with a parallel arrangement of their planes;

- with a three-axial (three-dimensional) arrangement of reinforcing filler and absence of a preferred direction in its arrangement.

According to the physical nature of their components, CMs are divided into the following large groups $[4,5]$ :

- composites containing components from various metals or alloys;

- composites containing within themselves components from various inorganic compounds (for example, oxides, carbides, nitrides, etc.);

- composites containing components from nonmetallic elements (including carbon, boron, etc.);

- composites containing components from organic compounds (for example, epoxy, polyester, phenolic resins and other chemical compounds).

As we see, CMs have a rather extensive classification. Below we will dwell in more detail on some of these composites.

2. The main technologies for manufacturing composites. Let us consider a number of composites, indicated above.

2.1. Fibrous composites. The mechanical characteristics of such $\mathrm{CM}$ are determined by the properties of a large number of parallel continuous fibers used in their composition. In each layer, the CM fibers 
can be woven into a fabric, which is an original shape whose dimensions correspond to the geometric parameters of the final material [1-5]. The matrix of such a composite should redistribute mechanical stresses between reinforcing fibers. Therefore, the strength and modulus of elasticity of the fibers used in such a composite must be significantly greater than the strength and modulus of elasticity of the matrix. Rigid reinforcing fibers perceive the mechanical stresses that occur in the composite when it is loaded with force, and also give it strength and rigidity in the direction of fiber orientation. For example, boron fibers, as well as fibers of refractory compounds (for example, carbides, nitrides, borides and oxides) with high strength and modulus of elasticity are used to harden aluminum, magnesium and their alloys in this case. Often used as a fiber wire of high-strength steels [1-5]. For the CM under consideration, when reinforcing titanium and its alloys, molybdenum wire, sapphire fibers, silicon carbide and titanium boride are used. The increase in the heat resistance of nickel alloys is achieved by reinforcing them with tungsten or molybdenum wires [1-5]. Metal fibers are also used in those cases where high values of thermal conductivity and electrical conductivity are required for the composite to be created. Prospective reinforcing fillers for high-strength and high-modulus fibrous CM are filamentary crystals of aluminum oxide and nitride, silicon carbide and nitride, boron carbide, etc. [1-5]. Composites on a metal base have high strength and heat resistance. At the same time, they are not very plastic. However, the reinforcing fibers in the $\mathrm{CM}$ reduce the propagation speed (on the composite) of the cracks that originate in the matrix. This almost completely eliminates the sudden brittle failure of CM. A distinctive feature of fibrous uniaxial CM is their anisotropy of mechanical properties along and across fibers and a low sensitivity to mechanical stress concentrators. The anisotropy of the properties of fibrous composites is taken into account when constructing machine parts (apparatus) from them to optimize the properties of CM by matching the resistance field with the fields of mechanical stresses in it. It was found that the reinforcement of aluminum, magnesium and titanium alloys with continuous refractory fibers of boron, silicon carbide, titanium boride and aluminum oxide significantly improves their heat resistance [1-5]. Thus, aluminum alloys reinforced with boron fibers can be reliably operated at temperatures up to (450-500) ${ }^{\circ} \mathrm{C}$ instead of $(250-300){ }^{\circ} \mathrm{C}$ [1-5]. The main disadvantage of composites with one- and twodimensional reinforcement by their fibers is the low resistance of $\mathrm{CM}$ to the interlayer shear and transverse breakage. This is deprived of materials with bulk fiber reinforcement [1-5].

2.2. Disperse-hardened composites. Unlike fibrous $\mathrm{CM}$ in dispersed-hardened composites, the matrix is the main element that carries an external force load, and their fillers (dispersed particles) inhibit the motion of dislocations in it (the matrix). In such $\mathrm{CM}$, high strength is achieved at a particle size (10-500) $\mathrm{nm}$, and also with an average distance between them (100-500) $\mathrm{nm}$ and uniform distribution of them in the matrix [1-5]. In these composites, the strength and high-temperature strength, depending on the volume content of the strengthening phases in their matrix, do not obey the additivity law. The optimal content of the second phase in the matrix for different metals in these CMs is not the same, but usually does not exceed (5-10) \% of the volume of the matrix material [1]. The use of stable refractory compounds (for example, thorium, hafnium, yttrium oxides, complex oxides compounds and rare earth metals) that do not dissolve in the matrix metal of the composite as hardening phases allows preserving the high strength of the CM material to temperatures approaching the melting temperature of the matrix metal [1 ]. In this regard, such $\mathrm{CM}$ are most often used as heat-resistant materials. Dispersion-hardened composites can be obtained on the basis of the majority of metals and alloys currently used in the technology (for example, aluminum, magnesium, nickel, copper, etc.) [1-5]. The most widely used similar CMs are aluminum-based alloys - SAP (sintered aluminum powder with $\mathrm{Al}_{2} \mathrm{O}_{3}$ oxide) [1]. The density of these $\mathrm{CM}$ is almost equal to the density of aluminum. They are not inferior to it for corrosion resistance and can even replace titanium and corrosion-resistant steels when operating in the temperature range $(250-500){ }^{\circ} \mathrm{C}$. For long-lasting strength, they exceed the deformable aluminum alloys. Thus, the long-term strength for alloys of the SAP-1 and SAP-2 type at $500{ }^{\circ} \mathrm{C}$ is (45-55) $\mathrm{MPa}$ [1]. According to materials scientists, there are great prospects for nickel dispersed-hardened materials. They found that nickel-based alloys with (2-3) \% thorium dioxide or hafnium dioxide had the highest heat resistance (1-5). Wide-range alloys of the type ВДУ-1 (nickel hardened with thorium dioxide), type ВДУ-2 (nickel hardened with hafnium dioxide) and ВДУ-3 type (nickel matrix $\mathrm{Ni}$ plus $20 \%$ by volume of chromium $\mathrm{Cr}$, hardened with thorium oxide $\mathrm{ThO}$ ). These alloys have high heat resistance. It should be noted that the introduction to these CMs (5-10) \% reinforcing fillers (refractory oxides, nitrides, borides and carbides) leads to an increase in the resistance of their metal matrix to force loads. The effect of increasing the strength of the material is comparatively small. However, it is valuable here to increase the heat resistance of the resulting composite as compared to the original matrix. Thus, the introduction of fine-dispersible powders of thorium oxide or zirconium oxide into the heat-resistant chromium-nickel alloy allows to increase the temperature at which products from this alloy are capable of prolonged operation, from 1000 to $1200{ }^{\circ} \mathrm{C}[1-5]$. We will point out that dispersed-hardened metal composites are obtained by introducing filler powder into the molten metal or by powder metallurgy methods [1-5]. Dispersion-hardened CM, as well as fibrous composites, are resistant to softening with an 
increase in the temperature acting on them and to the duration of exposure to the force loading [1-5].

2.3. Fiberglass. This composite is a composition consisting of a synthetic resin that is a binder and a fiberglass reinforcing filler. In this case, continuous or short glass fibers are usually used as the filler [1, 2]. It was found that the strength of glass fibers increases sharply with a decrease in its diameter. This feature is explained by the elimination of the effect on the strength properties of thin glass fibers of irregularities and cracks occurring in thick (with a large cross section) fiberglass. We note that the properties of glass fibers also depend on the content of alkali in its composition. The best strength parameters are for alkali-free glasses of aluminoborosilicate composition [1-5]. Glass fibers are usually made in the form of yarns, bundles (rovings), glass fabrics (Fig. 2), glass mats and chopped fibers [1]. Binder in these $\mathrm{CM}$ is polyester, phenol-formaldehyde, epoxy and silicone resins, polyimides, aliphatic polyamides, polycarbonates, etc.

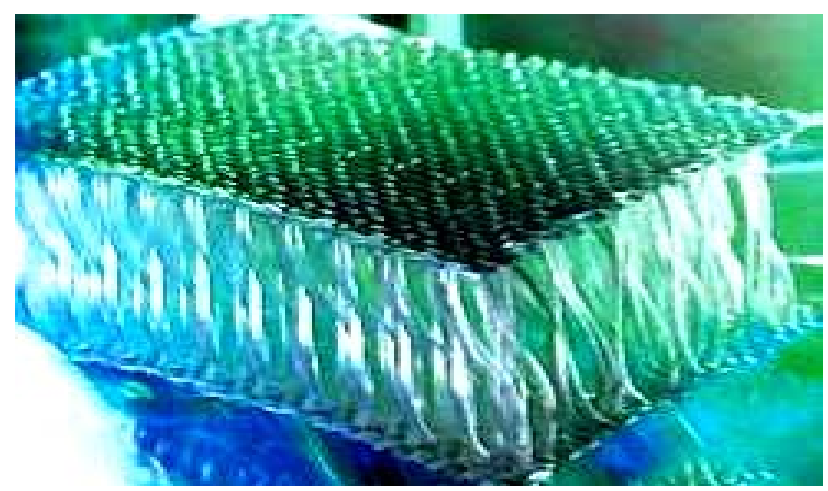

Fig. 2. General view of a fragment of the original glass fiber fabric of the type Parabeam 3D Glass fabric consisting of two woven horizontally placed parallel glass plates connected to each other by vertical glass worm and forming the so-called «sandwich-glass structure» [6]

Non-oriented glass fibers contain as a filler a short fiberglass. This makes it possible to press the details of complex shapes, including metal reinforcement [1]. In this case, the $\mathrm{CM}$ is obtained with isotropic strength characteristics, which are much higher than for press powders. Known representatives of such a composite are glass fibers of the АГ-4B type, as well as the DGF type (dosing glass fibers) [1-6]. They are widely used for the manufacture of power electrical components and parts of engineering products (for example, spools, seals of electric pumps, etc.). When these unsaturated polyesters are used as binder in these glass fibers, premixes like ПСК (pasty) and prepregs of the type АП and ППМ (based on the glass mat) are obtained [1]. Prepregs can be used for making light large-sized products of simple shapes (for example, car bodies, boat hulls and a number of devices) [1-6].

Oriented glass fibers contain a filler-reinforcing agent in the form of long glass fibers located in the CM oriented with separate strands and carefully glued together with a binder. Such a technology of their manufacture provides, in comparison with nonoriented glass fibers, a higher strength of the resulting glass fiber reinforced plastic [1-6]. These CMs can reliably operate under temperatures acting on them from «minus» $60{ }^{\circ} \mathrm{C}$ up to «plus» $200{ }^{\circ} \mathrm{C}$. They are able to withstand tropical atmospheric conditions and large inertial overloads [1]. It is known that penetrating ionizing radiation has little effect on their mechanical and electrical properties.

2.4. Carbon fiber. This kind of composite contains a binder polymeric matrix (based on phenol-formaldehyde or other resin) and a carbon fiber reinforcing filler (Carbon fiber) [1-6]. Carbon fiber is a new material consisting of thin filaments with a diameter of 3 to $15 \mu \mathrm{m}$, formed predominantly by carbon atoms. The carbon atoms (carbon) in these filaments are combined into microscopic crystals aligned parallel to each other. Alignment of these crystals gives the carbon fiber greater tensile strength. Carbon fibers are characterized by high tension force, low specific gravity, low coefficient of temperature expansion and chemical inertness [7]. Carbon fibers are obtained from synthetic and natural fibers based on cellulose, copolymers and acrylonitrile [1, 7]. When they are made, heat treatment of the fiber is used. It is usually carried out in three stages [7]: stage 1 - oxidation at temperature of $220{ }^{\circ} \mathrm{C}$; stage 2 - carbonization at temperatures (1000-1500) ${ }^{\circ} \mathrm{C}$; stage 3 - graphitization at temperatures (1800-3000) ${ }^{\circ} \mathrm{C}$ ). This technology leads to the formation of fibers characterized by a high content of carbon in them (up to $99.5 \%$ by mass). The high binding energy of atoms in carbon fibers allows them to retain their strength at very high temperatures (in a neutral medium up to $2200{ }^{\circ} \mathrm{C}$ ), and also at low temperatures [1-7]. From the oxidation of the surface, carbon fibers are protected by protective pyrolytic coatings. Unlike the glass fibers of carbon fiber, because of the low values of their surface energy, they are poorly wetted by the binder (matrix) used in the technologies for their production. Therefore, these fibers are etched before they are filled with a binder [1, 7]. This increases the degree of activation of carbon fibers by the content of the carboxyl group on their outer surface. Because of this, the interlayer shear strength for carbon plastics increases 1.6-2.5 times [1]. In addition, in the manufacture of the CMs under consideration, whiskerization of the filamentary carbon crystals with titan $\mathrm{TiO}$ is used, which provides an increase in the interlayer stiffness of carbon plastics up to two times and the strength is almost 2.8 times [1]. Often in the manufacture of carbon fiber they use spatially-reinforced structures. In this case, synthetic polymers serve as bonding agents (matrices), which also determines the name of the resulting composites-polymer carbon fibers. In the case where synthetic polymers are subjected to pyrolysis during the manufacture of $\mathrm{CM}$, the resulting composites are called coking carbon fibers. When used in the technology of production of the pyrolytic carbon composites under 
consideration, the $\mathrm{CM}$ obtained with it is called pyrocarbon carbon fiber [7].

Epoxyphenolic carbon fiber type КМУ-1л can operate for a long time at temperatures up to $200{ }^{\circ} \mathrm{C}$. Carbon fiber type КМУ-3 and КМУ-2л are obtained on the basis of epoxy anilinoformaldehyde binder, which serves as a polymer matrix. These composites are considered to be the most technologically advanced carbon fiber. They can be reliably operated at temperatures up to $100{ }^{\circ} \mathrm{C}$. Carbon fiber type KMУ-2 and КМУ-Зл based on polyamide binder can be used at temperatures up to $300{ }^{\circ} \mathrm{C}$. Carbon fibers are characterized by high statistical and dynamic fatigue resistance. They retain this property at normal and low temperatures (high thermal conductivity of the fiber prevents self-heating of the CM due to internal friction). They are water and chemically resistant. After the exposure of X-rays in air, their properties do not practically change [1-7].

Currently, one of the directions in obtaining new $\mathrm{CM}$ is the production of carbon fiber with a carbon matrix. At temperatures $(800-1500){ }^{\circ} \mathrm{C}$, carbonized carbonates are formed, and at (2500-3000) ${ }^{\circ} \mathrm{C}$, graphitized carbon fibers are formed $[1,7]$. To produce pyrocarbon materials, the reinforcement is laid out according to the shape of the article and placed in an oven through which an gaseous hydrocarbon is passed through the atmosphere (usually methane $\mathrm{CH}_{4}$ ). Under a certain regime (temperature $1100{ }^{\circ} \mathrm{C}$ and residual pressure $2660 \mathrm{~Pa}$ ), methane decomposes and the resulting pyrolytic carbon deposits on the reinforcing fiber, binding them. It should be noted that the coke formed during the pyrolysis of the binder has a high adhesion strength to the carbon fiber. In this regard, the $\mathrm{CM}$ obtained in this way has high mechanical and ablative properties, as well as high resistance to thermal shock. Carbon fiber with a carbon matrix of the type КУП-ВМ on the strength and toughness is 5-10 times higher than special graphites $[1,7,8]$. When heated in an inert atmosphere and vacuum, it retains its strength to temperatures of about $2200{ }^{\circ} \mathrm{C}$. In air, it oxidizes, starting at $450{ }^{\circ} \mathrm{C}$, and requires a protective coating.

The main advantages of carbon fibers in front of fiberglass are their lower density and higher modulus of elasticity [7]. Carbon plastics are light, strong and have practically zero coefficient of linear expansion. All types of carbon plastics conduct electricity well through themselves. High-temperature parts of rocket engines and high-speed aircraft, brake shoes and disks for jet planes and reusable spaceships and parts of electrothermal equipment are made of high-temperature carbon fiber [8].

2.5. Boron fibers. This $\mathrm{CM}$ is a composition made of a polymeric binder (matrix) and boron fibers (filler). Boron fibers (boron plastics) are distinguished by their high compressive strength, shear and shear, low creep, high hardness and elastic modulus, and thermal conductivity and electrical conductivity [1-8]. The cellular microstructure of boron fibers provides high strength of the CM at shear at the interface between them and its matrix. In the production technology of this composite, in addition to the continuous boron fiber, complex boron glasses are also used, in which several parallel boron fibers are intertwined with glass fiber that betrays them to form stability. The use of bored leaflets facilitates the technological process of manufacturing the $\mathrm{CM}$ under consideration. Modified epoxy and polyamide binders are used as matrices for the production of boron fibers. Boron fibers of type КМБ-1 and КМБ-1к are designed for continuous operation at temperatures up to $200{ }^{\circ} \mathrm{C}$, while КМБ-3 and КМБ-3к types do not require high pressure during processing and can operate at temperatures not higher than $100{ }^{\circ} \mathrm{C}$. КМБ-2к type boron fiber is operable at temperatures up to $300^{\circ} \mathrm{C}$ [1-8]. Boron fibers have high rates of fatigue resistance. They are resistant to the effects of penetrating radiation, water, organic solvents and various fuels and lubricants. In addition, for boron fibers, the compressive strength is 2-2.5 times greater than for carbon fiber strands [1]. At the same time, the high fragility of boron plastics makes their processing difficult and imposes restrictions on the shape of products obtained from boron fibers. The technological feature of obtaining boron fibers is that the necessary boron for them is precipitated from boron chloride to a tungsten matrix-substrate, the cost of which can reach up to $30 \%$ of the cost of the boron fiber obtained $[1,8]$. In this connection, the cost of boron fiber is today high and reaches USD $400 / \mathrm{kg}$ [8].

2.6. Organic fibers. These $\mathrm{CMs}$ are composites consisting of a polymeric binder (matrix) and reinforcing agents (fillers) in the form of synthetic fibers. Organic fibers have low mass, relatively high values of specific strength and rigidity. They are stable under the action of alternating loads and a sudden change in temperature [1-8]. In organic fibers the values of the modulus of elasticity and the temperature coefficients of linear expansion of the reinforcing agent (synthetic fibers) and the binder (polymeric compounds based on epoxy and other resins) are similar. Therefore, during their manufacture, the components of the binder are diffused into the fiber used and the chemical interaction between them. The structure of the resulting synthetic material is practically defect-free $[1,7]$. Its porosity does not exceed (1-3) \%. For comparison, note that in other CMs the porosity reaches values $(10-20) \%[1,7]$. The impact strength of organic fibers is high and equal to about (400-700) $\mathrm{Pa} \cdot[1,7]$. Hence, the stability of the mechanical properties of the organic fibers follows with a sharp temperature difference, the impact of shock and cyclic force loads. Organic fibers are resistant to the action of corrosive environments and the humid tropical climate. Their dielectric properties are high, and the thermal conductivity is low. Most organic fibers can work for a long time at temperatures $(100-150){ }^{\circ} \mathrm{C}$. Based on the polyamide binder and polyoxadiazole fibers, they are able 
to function reliably at temperatures $(200-300){ }^{\circ} \mathrm{C}[1,7]$. A disadvantage of these composites is their relatively low mechanical strength under compression and high creep.

2.7. Polymer nanocomposites. This type of CM is polymers filled with nanoparticles that interact with the polymer matrix not at the macrolevel (as in the case of conventional composites), but at the molecular level [9]. Due to this interaction, a composite is formed, which has a high adhesion strength of the polymer matrix to nanoparticles. As is known, nanoparticles have linear dimensions of not more than $100 \mathrm{~nm}$ in one of three spatial dimensions [10]. An analysis of recent domestic and foreign studies indicates a high potential for research in the field of polymeric nanocomposite materials [9]. Unfortunately, these works contain a lot of technological «know-how» and access to them is currently extremely limited [2].

2.8. Intermetallides. Such a name in materials science received new chemical compounds based on compositions of the type «titanium-aluminum», «nickelaluminum», etc. [9]. It is believed that it is intermetallics, as a new class of structural materials that can lead to revolutionary solutions in the development and creation of promising products for rocket and space technology. These composites have a relatively low density - from 3.7 to $6.0 \mathrm{~g} / \mathrm{cm}^{3}$ and have high heat resistance (up to $1200{ }^{\circ} \mathrm{C}$ ) [9]. In addition, they are characterized by high levels of corrosion resistance, heat resistance and wear resistance. Intermetallic titaniumbased alloys can operate up to $8500^{\circ} \mathrm{C}$ without protective coatings. Alloys based on nickel - up to $1500{ }^{\circ} \mathrm{C}$ [9]. In the opinion of specialists, the use of intermetallic compounds in propulsion systems (for example, for the rotor, stator, impeller, valve group, uncooled nozzles, etc.) will increase the specific thrust of the engines by (25-30) \%, and also provide a reduction in the mass of the designs of propulsion systems to $40 \%[2,9]$.

2.9. Eutectic composites. This type of $\mathrm{CM}$ is an alloy of a eutectic or close to eutectic composition, in which oriented crystals formed in the process of directional crystallization act as a strengthening phase [8]. Unlike ordinary CM, eutectic composites are produced in one technological operation. A directional oriented crystal structure can be obtained at the final stage of the product release. The geometric shape of the crystals formed during the corresponding operation can be in the form of fibers or plates. Directed crystallization methods already produce composites based on aluminum, magnesium, copper, cobalt, titanium, niobium and other chemical elements [8]. Therefore, these composites can be used in a wide range of temperatures [2].

2.10. Composites based on ceramics. Reinforcement of ceramic materials (matrices) with fibers, as well as metallic and ceramic dispersed particles, allows obtaining high-strength composites [8]. As a reinforcing filler, metal fibers are often used. In this case, the tensile strength increases insignificantly, but the resistance to thermal shocks increases significantly. Because of this, the ceramic material cracks less during its heating. The properties of the CM thus obtained will depend on the ratio of the thermal expansion coefficients of its matrix and filler. Reinforcement of ceramics with dispersed metal particles provides a new type of material cermet which has increased mechanical resistance, thermal conductivity and resistance to thermal shocks $[8,11]$. In both cases, ceramic composites are produced by hot pressing (tableting with subsequent sintering under pressure) or by slip casting (filler fibers are poured with a slurry of matrix material, which after drying is sintered in special furnaces) $[2,11]$.

2.11. Functional gradient materials. Such new types of composites as functional gradient materials (FGM) are alloys consisting of hard grains of carbides, nitrides and borides of transition metals (for example, tungsten carbide, titanium carbide, titanium carbonitride, titanium diboride, etc.) forming a strong continuous framework matrix), and a metal bond (from cobalt, nickel, titanium, aluminum, etc.), the content of which varies continuously in the volume of such CM [12]. Practical realization of the layered structure of FGM is ensured by layer-by-layer pressing of carbide press powders with different contents of the above-mentioned metal bond and different grain sizes of the solid phase followed by vacuum sintering. In this case, mass transfer of the metal bond during the liquid-phase sintering from a layer with a large grain size into a layer with a smaller grain size, leading to a gradient of its content in the alloy, will be observed in the CM under consideration. Such a CM manufacturing technology makes it possible to control the gradient in the «frame-binder» system for the composite under consideration by changing its (metal bond) concentration in the pressed layers of FGM. As a result, FGM have the properties of both a hard alloy and a metal. Therefore, such composites have high hardness, thermal stability and high impact strength $[2,12]$.

3. Basic properties and technical characteristics of composites. Let us dwell on the advantages, properties and disadvantages of a number of these CMs.

3.1. Advantages of composites. The main advantage of $\mathrm{CM}$ in comparison with traditional structural materials is that during the manufacture of a composite, the material and the construction of the product are created simultaneously [1-5]. CM specialists are always created for specific technical tasks and for a particular product. Therefore, the composite in its essence can not always be a priori better than the traditional material in everything. The main advantages of most of the known composites in the world are their following properties [1-9]:

- high mechanical strength (with a temporary resistance of up to $3500 \mathrm{MPa}$ );

- high mechanical rigidity (with modulus of elasticity from 130 to $240 \mathrm{GPa}$ ); 
- high corrosion resistance in corrosive environments and wear resistance of structures from CM;

- high fatigue mechanical strength;

- high heat and heat resistance (up to $1650{ }^{\circ} \mathrm{C}$ );

- high thermal protection properties of $\mathrm{CM}$;

- low coefficient of thermal expansion;

- low density and weight (mass) characteristics, which make the structures made with the use of CM easy;

- possibility of manufacturing from CM dimensionstable structures for various purposes.

3.2. Some properties of boron plastics. One of the most promising $\mathrm{CM}$ in the field of aircraft and rocket construction are boron fiber, made with the use of reinforcing boron fiber and epoxy matrices [13]. According to the results of foreign studies, the use of boron plastics makes it possible to reduce the weight of the final design of an aircraft (20-40\%), significantly increase its rigidity and increase the operational reliability of the product as a whole [13]. The specific strength ratios of boron plastics and, for example, aluminum alloys for stretching are 1.3-1.9, for compression 1.5, for shear 1.2 and for crushing 2.2. In addition, the boron plastics retain their properties in the temperature range from -60 up to $+177^{\circ} \mathrm{C}[2,13]$.

3.3. Some properties of carbon plastics. It is known that carbon plastics are characterized by a relatively low specific gravity (up to $1.5 \mathrm{~g} / \mathrm{cm}^{3}$ while the density of aluminum alloys is about $2.8 \mathrm{~g} / \mathrm{cm}^{3}$, and that of titanium alloys is $4.5 \mathrm{~g} / \mathrm{cm}^{3}$ [13]), high stiffness values, vibration and fatigue strength [1-9]. According to the data of [13], the mechanical strength and rigidity of carbon plastics is about six times higher than that of the main grades of steel used in aircraft designs. The carbon plastics are radio transparent (they pass electromagnetic waves well through themselves) [1-9]. Carbon fibers (carbon plastics) with a carbon matrix (with specific gravity up to $1.4 \mathrm{~g} / \mathrm{cm}^{3}$ ) have high heat-shielding properties and the ability to maintain their strength characteristics at temperatures up to $2500{ }^{\circ} \mathrm{C}[7,13]$.

3.4. Some properties of boron aluminum. In this $\mathrm{CM}$ with a matrix of aluminum alloys, boron fibers (sometimes coated with silicon carbide $\mathrm{SiC}$ ) are used as the reinforcing filler [13]. Boron aluminum is 3.5 times lighter than aluminum and twice as strong as aluminum, which makes it possible to obtain significant weight savings for a number of aircraft designs. In addition, at high temperatures (up to $430{ }^{\circ} \mathrm{C}$ ), the boron aluminum composite has twice the values of mechanical strength and stiffness compared to titanium [13]. Therefore, boron aluminum can compete with titanium when used in supersonic aircraft with flight speeds of about three Mach numbers (at present, only titanium alloys are used as structural material in such aircraft) [13].

3.5. Disadvantages of composites. All CMs known to date in the world have a number of significant shortcomings that hinder their wider application in various areas of modern technology [1-9]:
- high cost, which is due to the high science-intensive production of $\mathrm{CM}$, the need to use special expensive equipment and raw materials in the CM technology;

- anisotropy of properties, leading to the dependence of the physico-mechanical characteristics of CM from the choice of the direction of their measurement in the finished product;

- low impact strength, which determines the choice of an increased safety factor for the product, and as a result increased consumption of expensive CM and an increased probability of concealed defects in the product;

- high specific volume of CM in the product, which is unacceptable in areas with a strict limitation of occupied volume (for example, when creating supersonic aircraft, for which even a slight increase in the volume of elements leads to a sharp increase in wave drag);

- hygroscopicity, caused by the incompleteness of the internal structure of $\mathrm{CM}$ and, accordingly, propensity to absorb atmospheric moisture;

- toxicity caused by the release of toxic fumes from the structure of CM during their long-term operation;

- low operational manufacturability leading to low repairability of composites and high cost of operation of products in the construction of parts of which CM is used.

4. The main applications of composites in engineering. Areas of use of CM are not limited. The introduction of composites into modern technology provides a new qualitative leap in increasing the power of engines, power plants and vehicles, reducing the weight (mass) of machines and devices. Practical application of $\mathrm{CM}$ in modern technology will be considered on a number of examples.

4.1. Aviation and rocket and space technology. CMs with a metal matrix, reinforced with filamentary single crystals («whiskers»), were created in the early 1970s purposefully for aviation and space structures of aircrafts [8]. Filamentary crystals for composites are prepared by pulling a suitable melt through spinnerets. For these technical purposes, the «whiskers» of sapphire (aluminum oxide $\mathrm{Al}_{2} \mathrm{O}_{3}$ ) and beryllium, boron and silicon carbides, as well as aluminum, silicon and other chemical elements of length (0.3-15) mm and diameter (1-30) $\mu \mathrm{m}$ are used [8, 11]. Reinforcement of the «whiskers» of many metals can significantly increase the strength of the material being created and increase its heat resistance. Thus, the yield stress of a composite composed of silver containing $24 \%$ «whiskers» of aluminum oxide is 30 times higher than the yield strength of silver and twice as many silver-based CMs [11]. The reinforcement of «whiskers» made of aluminum oxide composites based on refractory metals tungsten and molybdenum doubles their mechanical strength at a working medium temperature up to 1650 ${ }^{\circ} \mathrm{C}$ [11]. This made it possible to use these heat-resistant CMs with a metal matrix in the manufacture of heatresistant nozzles for most liquid and solid-fuel rocket engines for peaceful and military launch vehicles. 
The use of boron plastics in modern technology is limited, above all, by the high cost of producing boron fibers used in them (up to USD $400 / \mathrm{kg}$ [8]). In this connection, they are used mainly in products of aviation and rocket and space technology in parts and assemblies subjected to long-term power loads under the influence of an aggressive medium [8]. Due to the qualities mentioned above (see paragraphs 2.4 and 3.3), carbon plastics are considered to be very promising for the manufacture of those parts and units of airplanes that operate at high temperatures, as well as for heat shields of aircrafts and, above all, spacecraft [13]. Note that initially (in the 1970s) the use of carbon plastics in aircraft designs was insignificant (due to the high cost of carbon fiber, up to USD $900 / \mathrm{kg}$ ) [13]. At the beginning of the 21st century, this cost was already about USD $150 / \mathrm{kg}$. According to the forecasts of American specialists, the cost of carbon fiber will soon be up to USD $80 / \mathrm{kg}$. Based on the information given in Section 3.4, boron aluminum can also be considered one of the promising CMs, the use of which in aircraft construction can give up to $50 \%$ of the weight savings of aircraft designs $[11,13]$.

Fig. 3 shows a general view of the Russian mediumhaul passenger aircraft of the Tu-204 type, in the designs of parts (assemblies) of which at the beginning of the $21 \mathrm{st}$ century the share of CM was up to $25 \%$ [14]. We will point out that the proportion of using composites on a new Russian aircraft of the MC-21 type, developed by the «Irkut» Corporation, will amount to as much as $37 \%$.

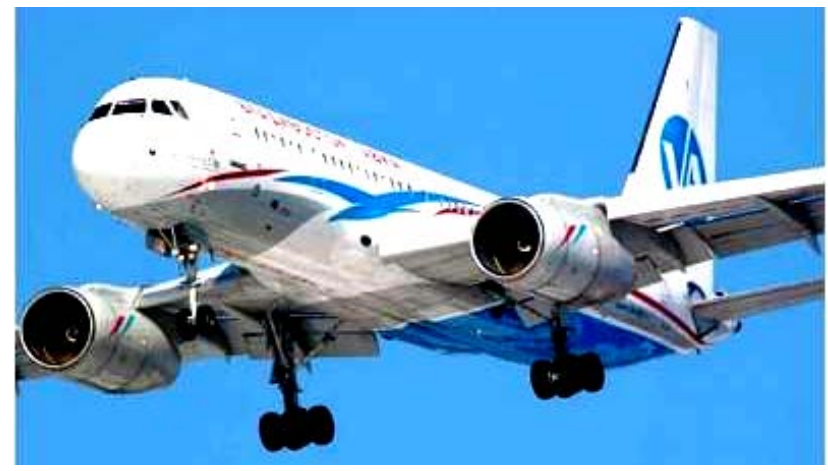

Fig. 3. The general view of a medium-haul passenger aircraft of the Tu-204 type (RF, 1990's) in which up to $25 \%$ of all parts of the glider were made of composites [14]

World leaders in aircraft construction - the corporations Airbus and Boeing are also actively using composites in the designs of their aircraft. If only (10-15) \% of CM from the weight of the liner was used in their A-340 and B-777 aircraft in 2000, then in 2015 this figure was not less than $50 \%$ [14]. Fig. 4 shows the general view of the American trunk passenger aircraft type Boeing 787 Dreamliner in which the share of CM by mass (weight) exceeds $50 \%$ [14].

It is known that the use of polymer $\mathrm{CM}$ in the production of aviation and space technology can reduce from 5 to $50 \%$ weight (mass) of aircraft $[11,13]$. At the same time, it should be noted that the reduction in weight (mass), for example, of an artificial Earth satellite when it is brought to a near-earth orbit by $1 \mathrm{~kg}$ leads to savings of money up to USD 1000 [11]. In this regard, the tasks of the practical application of CM in the objects of rocket and space technology are today not only relevant and promising, but as defining and strategic tasks for developers and creators of this high technology.

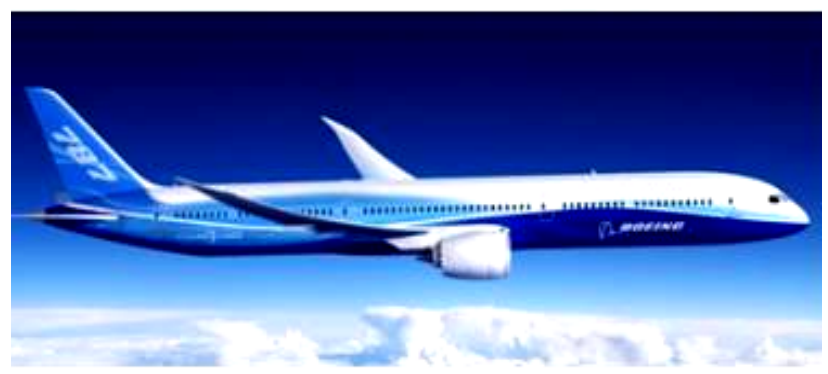

The general view of the main passenger aircraft of the type Boeing 787 Dreamliner (USA, 2015) the fuselage and wings of which were $90 \%$ made of composites [14]

Using the world experience of using CM in civil and military aircraft designs and taking into account the high mechanical and thermal protection properties of polymer CM, US specialists came to the conclusion that carbon fiber composites with a carbon matrix are used in the manufacture of strategic missile warheads $[13,15]$.

It should be noted that a number of critical parts of artificial earth satellites (for example, the frames of their radio antenna series) are already made of carbon plastic in combination with an aluminum honeycomb structure $[11,15]$. Let us emphasize that at the present time, due to the special importance and availability of many technological know-how for the production in the world of high-quality carbon fiber and, accordingly, the technology for making various carbon plastic materials with it, are closed «with seven locks». According to authoritative scientists, no more than two or three countries own such technologies in the world today [16]. You can not buy them by purchasing the appropriate licenses from the developer. Therefore, many interested firms, working especially in the field of aerospace engineering, face a dilemma: [16] «Either you buy a finished product (for example, an aircraft in which carbon fiber is used in the form of parts). Either you need to develop the necessary technology for the production of good carbon fiber».

Fig. 5 shows the general view of the orbital compartment of the new American spacecraft Liberty for transportation of astronauts and scientific equipment to the International Space Station (ISS) [17]. The light housing of the compartment was made of polymer CM based on carbon fiber [17].

We point out that at the Scientific-\&-Research Planning-\&-Design Institute «Molniya» of the NTU «KhPI» in recent years, in conjunction with the State Enterprise «Antonov», the I.N. Frantsevich Institute for Problems of Materials Science of the National Academy 
of Sciences of Ukraine and Boeing Corporation, certification tests of prototype of sheet specimens with dimensions in the plan of $500 \times 500 \mathrm{~mm}$ of a number of $\mathrm{CMs}$ intended for the manufacture of composite cladding of domestic and foreign passenger airplanes (including the Boeing 787 Dreamliner [14]), on the resistance to direct action of pulsed current of artificial lightning on them [18] were carried out.

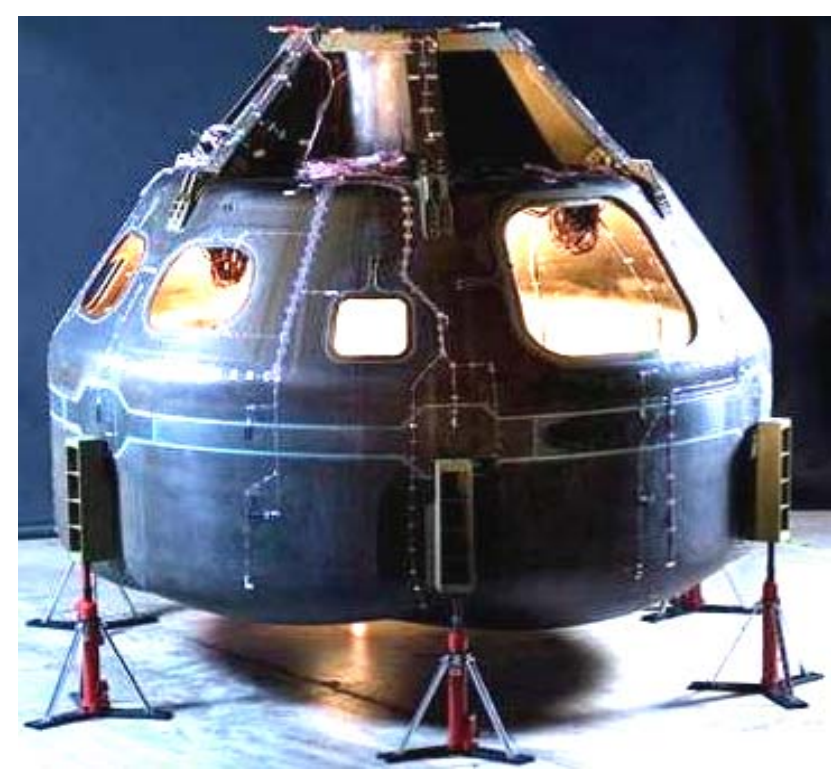

Fig. 5. The general view of the orbital compartment of the new spaceship Liberty (USA) made on $90 \%$ of polymer composites and intended for the re-delivery of astronauts and scientific cargoes on board the ISS [17]

These tests were performed on a unique generator of artificial lightning current type УИТОМ-1 developed and created at our Institute (at the Department No. 4 for Electromagnetic Investigations) which generates a pulsed $A$ - and long-time $C$ - components of the simulated thunderstorm air current at the tested technical facility with normalized amplitude-temporal parameters (ATPs) [19]. In addition, these high-current high-voltage tests were conducted in accordance with the stringent requirements of the current US regulations SAE ARP 5412 and SAE ARP 5416 [20, 21]. As a result of longterm tests (with a total number of tested at the working table of the generator УИТОМ-1 of different composition and identical by the geometric dimensions of experimental samples of sheet composites of not less than 250 pieces), stable CMs were determined to directly affect the specified normalized [21] the component of the pulsed current of artificial lightning with limiting ATPs (at amplitude $I_{m A}$ of the pulsed $A$ - component of the current of negative polarity with a front duration $\leq 50 \mu \mathrm{s}$ equal to $(200 \pm 20) \mathrm{kA}$, the action integral of the pulsed $A$ - component $(2 \pm 0.4) \cdot 10^{6} \mathrm{~J} / \Omega$, the duration of the pulsed $A$ - component of current $\leq 500 \mu \mathrm{s}$, the amplitude $I_{m C}$ of the long $C$ - component of negative polarity current equal to (0.2-0.8) kA, charge of a long $C$ - current component equal to $(200 \pm 40) \mathrm{K}$, the duration of the flow of a long $C$ - current component equal to (0.25-1) s [18]).

Fig. 6 shows the external view of the rounded damage zone (up to $100 \mathrm{~mm}$ in diameter) of the experimental sheet specimen of the $3 \mathrm{~mm}$ thick composite lining (with its dimensions in the plan of $500 \times 500 \mathrm{~mm}$ ) when it is exposed to only a pulsed $A$-component of the artificial lightning current with an amplitude equal to $I_{m A} \approx-212 \mathrm{kA}$ [18]. The multilayered composite of this sample had in its composition layers of fiberglass with an epoxy matrix, layers of carbon fiber with an epoxy phenol matrix, and layers of thin metal meshes acting as a reinforcing agent $[7,18]$.

4.2. Mechanical engineering. In the machine building industry, CM is widely used to create hard coatings on the cutting tool and protective coatings on metal surfaces with intense friction, and also for the manufacture of various parts of internal combustion engines (e.g. pistons, connecting rods, etc.) $[1-9,22]$. In this case, solid structures of titanium carbide TiC are used to create wear-resistant coatings on the cutting tool [22], and for a protective coating a number of functionally different materials can be used [2, 11]: inorganic materials (modified by various additives, magnesium, iron and aluminum silicates); polymeric materials (polytetrafluoroethylenes modified with ultradisperse diamond-graphite powders and ultrafine powders of soft metals); organometallic materials containing an increased number of acidic functional groups. Due to the formation of high-strength metal-ceramic, polytetrafluoroethylene and organometallic layers on the protected surfaces in the local zone of high power loads (due to phase transitions and plasticization processes), the protective composite coatings formed are characterized by the following properties [1-9]: high adhesion to the surface of the protected metal; high purity of the working surface (up to grade 9); low porosity (at pore sizes up to $3 \mu \mathrm{m}$ and coating thickness up to $100 \mu \mathrm{m}$ ); low coefficient of friction (up to 0.01).

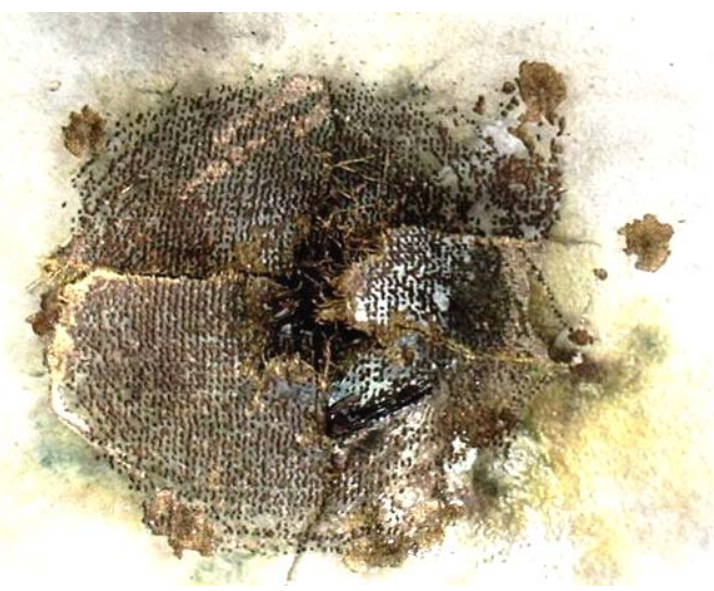

Fig. 6. The results of the action of an artificial lightning current pulse $\left(I_{m A} \approx-212 \mathrm{kA}\right)$ on a prototype aircraft skin made of multilayer $\mathrm{CM}$ using fiberglass, carbon fiber, and metal mesh [18] 
4.3. Special fields of technology. From hightemperature cermets now make parts for jet aircraft and space technology, gas turbines, as well as various armature electric furnaces [11]. Solid wear-resistant cermets are used for the manufacture of cutting tools. In addition, cermets are used in special fields of engineering in the manufacture of fuel elements of atomic reactors based on natural uranium oxide ${ }_{92}^{238} \mathrm{U}$, friction materials for brake systems of various devices, etc. [11].

FGM can be effectively used in the following technical areas [12]: in military equipment (making bulletproof vests and protecting tanks and helicopters from bullet and fragmentation); for metalworking (making cutters for processing hard-to-work steels and alloys); in the mining industry (making cutters for rock drilling); in the processing industry (lining grinders for grinding solids), etc.

Dispersion-hardened composites based on sintered aluminum alloy SAP are used in the manufacture of blades of powerful compressors, fans and steam turbines [11]. CM containing reinforced filamentary single crystals have found application in the manufacture of gas turbine blades, which are made of nickel alloys reinforced with crystalline yarn of sapphire (aluminum oxide $\mathrm{Al}_{2} \mathrm{O}_{3}$ ) [7, 9]. This makes it possible to significantly increase the temperature of superheated steam at the inlet to the turbine (note that the ultimate strength of sapphire single crystals at a temperature of $1680{ }^{\circ} \mathrm{C}$ is not less than $\left.700 \mathrm{MPa}[11-17]\right)$ and, accordingly, to increase its efficiency.

Such composites known as from the middle of the 20th century as various types of textolites (in these $\mathrm{CM}$ as a filler, fabrics from various fibers - cotton, synthetic, glass, carbon, asbestos, basalt, etc.) and wood-laminated plastics based on phenol-formaldehyde resin have found application in high-voltage high-current electrical engineering in the manufacture of power units and loadbearing elements of insulating structures of powerful electrophysical installations for scientific and technological purposes [18].

\section{Conclusions.}

1. Metal and non-metallic composites, because of their high physical and mechanical characteristics, have already found wide practical application in many areas of modern technology (in aviation technology for highly loaded parts of aircraft and their engines, in space technology for power units of aircrafts subjected to intense heating and large overloads, elements of rigidity and thermal protection of aircraft, in the reactor building for nuclear power plants, in mechanical engineering for the creation of solid and protective coatings, etc.; before and in the automotive industry for the production of propellers and for the facilitation of bodies, frames, auto panels, etc., in turbine construction for the production of blades, in the chemical industry for autoclaves and tanks for storing and transporting chemical and petroleum products, in the mining industry in the manufacture of drilling tools, parts underground combines, etc., in civil engineering in the performance of spans of bridges, elements of prefabricated structures of high-rise structures, etc.; in high-voltage impulse technology for the manufacture of such reinforced insulation materials as fiberglass, wood-laminated plastic grade ДСПБ-Э, bakelite, bakelized plywood, etc.).

2. The complex scientific and technical task facing the producers of composites in the world is the development of new technologies for their manufacture with lower costs that would make the CM competitive with respect to traditional metals and alloys that are also involved in the struggle for a leading role in the production of future technology.

3. Composites can become for humanity a constructional material for the near future. It is these synthetic materials that successfully combine high mechanical strength with their high modulus of elasticity and low density.

\section{REFERENCES}

1. Available at: https://en.wikipedia.org/wiki/Composite material (accessed 13 June 2015).

2. Available at: http://www.e-plastic.ru/main/articles/r2/pk01. (accessed 12 May 2016). (Rus).

3. Piatti J. Dostizhenija v oblasti kompozicionnyh materialov [Achievements in the field of composite materials]. Moscow, Metallurgy Publ., 1982. 304 p. (Rus).

4. Available at: http://www.mtomd.info/archives/1764 (accessed 03 March 2014). (Rus).

5. Vasil'ev V.V. Mehanika konstrukcij iz kompozicionnyh materialov [Mechanics of composite structures materials]. Moscow, Metallurgy Publ., 1988. 272 p. (Rus).

6. Available at: http://stroimsamolet.ru/057.php (accessed 21 October 2015). (Rus).

7. Available at: http://www.hccomposite.com/catalog/40/131 (accessed 10 May 2016). (Rus).

8. Available at: http://www.mtomd.info/archives $/ 1764$ (accessed 20 April 2015). (Rus).

9. Available at: http://www.zadachi.org.ru/? $\mathrm{n}=150240$ (accessed 15 August 2014). (Rus).

10. Baranov M.I. An anthology of outstanding achievements in science and technology. Part 13: Nanotechnologies. Electrical engineering \& electromechanics, 2013, no.2, pp. 3-13. (Rus). doi: 10.20998/2074-272X.2013.2.01.

11. Available

http://www.krugosvet.ru/enc/nauka i tehnika/himiya/KOMPOZ ITSIONNIE MATERIALI.html?page $=0,0$ (accessed 12 May 2015). (Rus).

12. Available at: http://dic.academic.ru/dic.nsf/ruwiki/367846 (accessed 02 January 2013). (Rus).

13. Available

at: http://pentagonus.ru/publ/1976/kompozicionnye materialy v a viastroenii_1976/126-1-0-1942 (accessed 01 May 2013). (Rus). 14. Available at: http://olymp.asclub.ru/publ/raboty 1 go tura/gotovye raboty/k ak___gde_v_samoletostroenii_ispolzujutsja_kompozicionnye materialy/6-1-0-825 (accessed 21 September 2015). (Rus). 15. Available at: http://www.spblp.ru/ru/magazine/82/183 (accessed 11 November 2016). (Rus). 
16. Available at: http://olgamwill.livejournal.com/5463.html (accessed 18 June 2015). (Rus).

17. Available at:

http://rnd.cnews.ru/news/top/index_science.shtml?2012/05/12/4 89249 (accessed 22 April 2014). (Rus).

18. Baranov M.I. Izbrannye voprosy elektrofiziki. Tom 2, Kn. 2: Teoriia elektrofizicheskikh effektov $i$ zadach [Selected topics of Electrophysics. Vol.2, Book 2. A theory of electrophysical effects and tasks]. Kharkiv, Tochka Publ., 2010. 407 p. (Rus).

19. Baranov M.I., Koliushko G.M., Kravchenko V.I., Nedzel'skii O.S., Dnyshchenko V.N. A Current Generator of the Artificial Lightning for Full-Scale Tests of Engineering Objects. Instruments and Experimental Technique, 2008, no.3, pp. 401405. doi: 10.1134/s0020441208030123.

20. SAE ARP 5412: 2013. Aircraft Lightning Environment and Ralated Test Waveforms. SAE Aerospace. USA, 2013.pp. 1-56.

21. SAE ARP 5416: 2013. Aircraft Lightning Test Methods. SAE Aerospace. USA, 2013. - pp. 1-145.

How to cite this article:

Baranov M.I. An anthology of the distinguished achievements in science and technique. Part 41: Composite materials: their classification, technologies of making, properties and application domains in modern technique. Electrical engineering \& electromechanics, 2017, no.6, pp. 3-13. doi: 10.20998/2074-272X.2017.6.01.
22. Vereshchaka A.S., Tret'yakov I.P. Rezhushchie instrumenty $s$ iznosostojkimi pokrytijami [Tool pieces with wearproof coverages]. Moscow, Engineering Publ., 1986. 192 p. (Rus).

Received 10.10.2016

M.I. Baranov, Doctor of Technical Science, Chief Researcher, Scientific-\&-Research Planning-\&-Design Institute «Molniya» National Technical University «Kharkiv Polytechnic Institute», 47, Shevchenko Str., Kharkiv, 61013, Ukraine, phone +380 577076841 ,

e-mail: baranovmi@kpi.kharkov.ua 